\title{
Pengaruh Penambahan Phase Change Material (PCM) Pada Pemanas Air Kolektor Tabung Dilengkapi Dengan Reflektor Double - U
}

\author{
Veni Dwi Sulastri ${ }^{11^{\star}}$, Hary Sutjahjono ${ }^{2)}$, Ahmad Syuhri ${ }^{2)}$ \\ 1) Jurusan Teknik Mesin Fakultas Teknik Universitas Jember \\ 2) Jurusan Teknik Mesin Fakultas Teknik Universitas Jember
}

Naskah diterima 24 Mei 2019; direvisi 22 September 2019; disetujui 28 Oktober 2019 doi: https://doi.org/10.24843/JEM.2019.v12.i02.p02

\begin{abstract}
Abstrak
Pemanas air energi surya merupakan suatu sistem pemanas air dengan cara kerja menyerap energi radiasi matahari yang kemudian diubah menjadi energi panas dan ditransfer menuju fluida kerja melalui pipa air. Pemanas air ini dibagi menjadi dua yaitu pemanas air kolektor tabung dan pemanas air kolektor plat datar. Dilakukan penelitian dengan menambahkan bahan Phase Change Material (PCM) yaitu sebuah material yang dapat menyimpan energi panas pada pemanas air kolektor tabung dilengkapi dengan reflektor double-U. Variabel pada penelitian ini yaitu pemanas air kolektor tabung tanpa menggunakan PCM dan menggunakan PCM, serta variasi laju aliran massa 0,008 kg/s, 0,010 kg/s, dan 0,030 kg/s. Bahan PCM yang digunakan yaitu campuran parafin $70 \%$ dan minyak goreng $30 \%$. Tujuan dari penelitian ini yaitu untuk mengetahui pengaruh penambahan PCM terhadap temperatur air dan efisiensi dari pemanas air kolektor tabung. Hasil dari penelitian menunjukkan bahwa efisiensi tertinggi terjadi pada pemanas air kolektor tabung menggunakan PCM dengan laju aliran massa $0,030 \mathrm{~kg} / \mathrm{s}$ yaitu sebesar $53,11 \%$.
\end{abstract}

Kata kunci: Pemanas air kolektor tabung, PCM, laju aliran massa

\section{Abstract}

Solar water heater is a system that can absorb solar radiation energy and converted it into heat energy and transferred to the fluid of water pipe. Solar water heaters are divided into two types, that are tube collector water heater and flat plate collector water heater. The study was conducted by adding Phase Change Material (PCM), a material that can store heat energy in the tube collector water heater equipped with a double-U reflector. The variables in this study were tube collector water heaters without using PCM and tube collector water heaters using PCM, as well as variations in mass flow rates of $0.008 \mathrm{~kg} / \mathrm{s}, 0.010 \mathrm{~kg}$ / s, and $0.030 \mathrm{~kg} / \mathrm{s}$. The PCM material used is $70 \%$ of paraffin and $30 \%$ of cooking oil. The purpose of this study is to determine the effect of adding PCM to water temperature and efficiency of tube collector water heaters. The results of the study showed that the highest efficiency occurred in tube collector water heaters using PCM with a mass flow rate of $0.030 \mathrm{~kg} / \mathrm{s}$ which was equal to $53.11 \%$.

Keywords: tube collector water heater, PCM, mass flow rate

\section{Pendahuluan}

Ketersediaan energi radiasi matahari di daerah tropis khususnya Indonesia cukup berlimpah yaitu sekitar $4,8 \mathrm{kWh} / \mathrm{m}^{2}$ [1]. Salah satu pemanfaatan energi radiasi yaitu sebagai pemanas air energi surya. Dalam memanaskan air digunakan suatu komponen untuk mengumpulkan energi radiasi matahari yang kemudian mengubahnya menjadi energi panas dan mentrasfer panas menuju fluida kerja [2]. sistem ini biasa disebut dengan kolektor surya. Berdasarkan bentuknya kolektor dibagi menjadi dua jenis yaitu kolektor plat datar dan kolektor tabung. Saat ini, banyak industri industri maupun rumah tangga menggunakan pemanas air kolektor tabung dari pada kolektor plat datar sebagai pemanas air karena kolektor tabung dapat mengurangi terjadinya heat loss [3].

Begitu banyak pengembangan yang dilakukan pada kolektor tabung. Salah satunya yaitu penambahan reflektor. Tujuan menggunakan reflektor adalah untuk meningkatkan kinerja serta mengurangi heat loss pada pemanas air kolektor tabung [4]. Reflektor diletakkan pada bagian bawah kolektor dan berfungsi sebagai penangkap radiasi yang tidak mengenai kolektor yang kemudian dipantulkan kembali menuju kolektor sehingga radiasi yang diserap menjadi lebih maksimal [5]. Telah dilakukan pengembangan pada bentuk reflektor salah satunya tipe double - U. Berdasarkan pola pantulannya, reflektor ini dianggap dapat meningkatkan efektifitas pada kolektor [6].

PCM (Phase Change Material) merupakan sebuah material yang dapat menyimpan panas dan mengalami perubahan fasa namun tidak mengalami perubahan struktur atau susunan kimia. Menurut penelitian yang ada, PCM dapat meningkatkan performa pemanas air kolektor tabung karena dapat mengurangi heat loss [7]. PCM dibagi menjadi 3 jenis diantaranya organik, non organik, dan eutektik. Parafin merupakan salah satu jenis PCM organik yang memiliki nilai kondutkivitas termal yang rendah, titik lebur rendah, serta mudah terbakar [8]. Oleh karena itu penulis melakukan penelitian mengenai pengaruh penambahan PCM pada pemanas air kolektor tabung dengan menggunakan reflektor tipe double U. PCM yang digunakan yaitu $70 \%$ parafin yang dicampur 
dengan $30 \%$ minyak goreng yang bertujuan untuk meningkatkan konduktivitas termal dari parafin.

\section{Metode Penelitian}

Metode yang digunakan pada penelitian ini yaitu metode eksperimental yang mana dilakukan pengamatan eksperimen secara langsung untuk mengetahui pengaruh penambahan PCM melalui perubahan temperatur dan efisiensi pemanas air kolektor tabung. Penelitian ini dibagi menjadi 2 tahap yaitu pembuatan prototype pemanas air kolektor tabung, dan pengambilan data. Desain kolektor disajikan pada gambar 1 dan 2 .

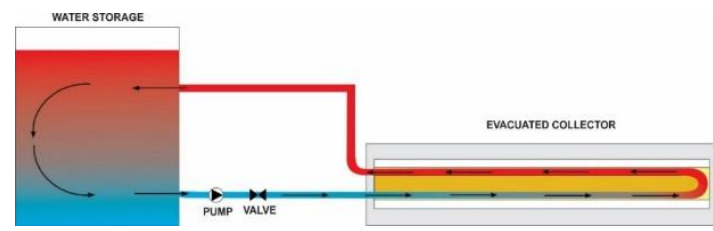

Gambar 1. Laju aliran air pada kolektor

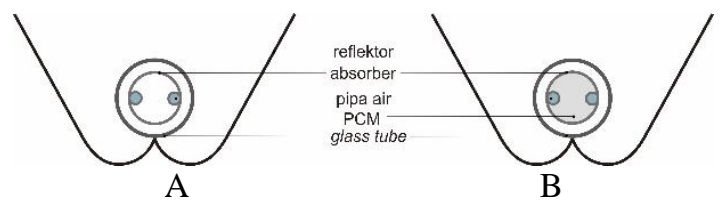

Gambar 2. Posisi kolektor tabung pada reflektor;

(A)Tanpa PCM ; (B) Menggunakan PCM

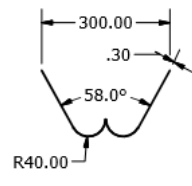

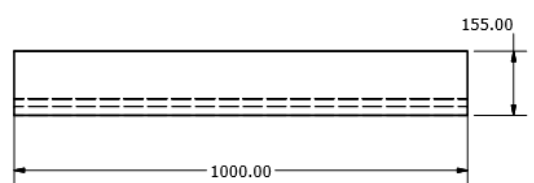

Gambar 3. Dimensi reflektor double $U$

Pengambilan data dilakukan dengan membandingkan kolektor tabung tanpa menggunakan PCM (kolektor A) dan menggunakan PCM (kolektor B) dengan variasi laju aliran massa 0,008 kg/s, 0,010 $\mathrm{kg} / \mathrm{s}$, dan $0,030 \mathrm{~kg} / \mathrm{s}$ saat proses charging dengan menggunakan lampu sebagai simulasi radiasi matahari.

\section{Hasil dan Pembahasan}

\subsection{Temperatur outlet air}

Penambahan PCM mempengaruhi temperatur outlet air. Adapun grafik temperatur pada outlet pemanas air kolektor tabung pada proses charging dengan laju aliran 0,008 kg/s, 0,010 kg/s, dan 0,030 $\mathrm{kg} / \mathrm{s}$ disajikan dalam gambar 4 .

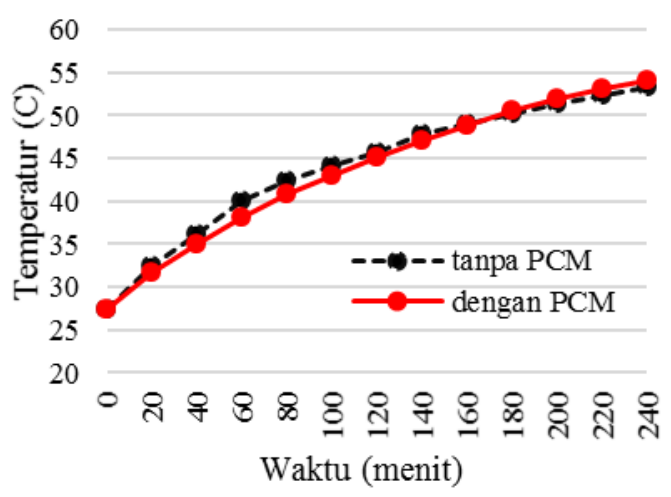

(a)

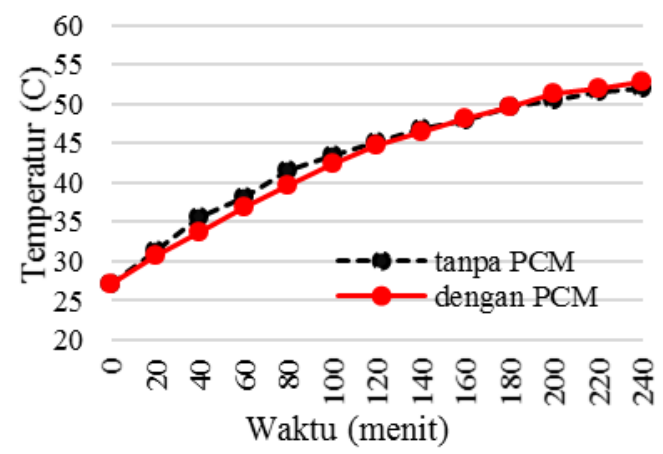

(b)

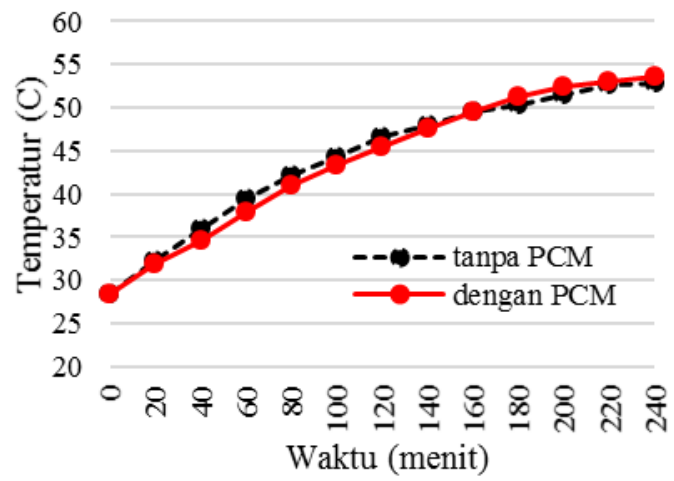

(c)

Gambar 4. Temperatur outlet air; (a) laju aliran massa 0,008 kg/s; (b) laju aliran massa 0,010 kg/s; (c) laju aliran massa $0,030 \mathrm{~kg} / \mathrm{s}$

Gambar 4 menunjukkan bahwa kolektor menggunakan PCM (B) lebih efektif dalam menyerap panas daripada kolektor tanpa PCM (A). Pada menit ke 0 - 140, kolektor A memiliki temperatur outlet lebih tinggi daripada kolektor $\mathrm{B}$. Hal ini disebabkan panas pada kolektor A diserap langsung oleh fluida kerja. Sedangkan pada kolektor B panas diserap oleh PCM dan fluida kerja. Kemudian pada menit ke 160 temperatur outlet dari kolektor A dan kolektor B berpotongan sehingga pada menit ke $180-240$ kolektor B memiliki temperatur outlet lebih tinggi. Hal ini disebabkan PCM mengalami fase transisi dari padat sebagian menjadi cair sepenuhnya sehingga pada kolektor $\mathrm{B}$ dapat menyerap panas lebih banyak daripada kolektor $\mathrm{A}$.

Berdasarkan data hasil penelitian, rentang temperatur outlet dari menit ke - 0 hingga 240 berbeda disetiap laju aliran massa. Rentang outlet pada laju aliran massa $0,008 \mathrm{~kg} / \mathrm{s}$ adalah $25,850 \mathrm{C}$ dan 26,8 oC pada kolektor $A$ dan kolektor $B$, pada laju 
aliran massa $0,010 \mathrm{~kg} / \mathrm{s}$ adalah 24,8 oC dan 25,6 oC pada kolektor $\mathrm{A}$ dan kolektor $\mathrm{B}$, dan pada laju aliran massa $0,030 \mathrm{~kg} / \mathrm{s}$ adalah 24,4 oC dan 25,2 oC pada kolektor A dan Kolektor B. Dapat disimpulkan bahwa semakin rendah laju aliran massa, maka akan semakin tinggi rentang temperatur outlet pada kolektor. begitu juga sebaliknya. Namun rentang tersebut tidak terlihat signifikan karena air mengalir secara sirkulasi.

\subsection{Selisih inlet dan outlet air}

Berikut grafik selisih antara inlet dan outlet air pemanas air kolektor tabung pada kolektor $\mathrm{A}$ dan kolektor B dengan laju aliran massa $0,008 \mathrm{~kg} / \mathrm{s}, 0,010$ $\mathrm{kg} / \mathrm{s}$, dan $0,030 \mathrm{~kg} / \mathrm{s}$.

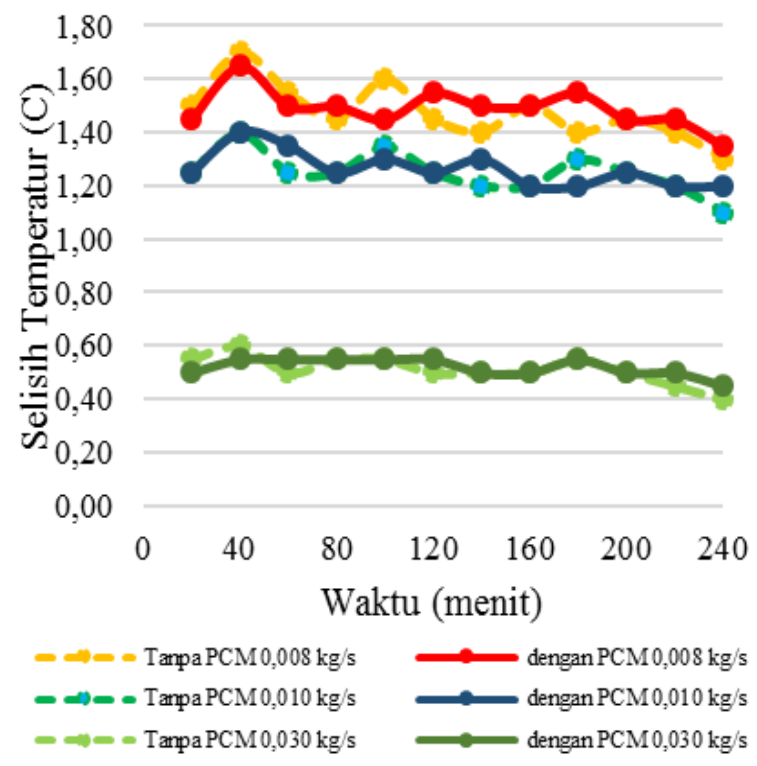

Gambar 5. Selisih inlet dan outlet air kolektor

Tabel 1. Selisih inlet dan outlet kolektor tabung

\begin{tabular}{ccc|cc}
\hline $\begin{array}{c}\text { Laju aliran } \\
\text { massa }\end{array}$ & \multicolumn{2}{c|}{$\begin{array}{c}\text { Kolektor } \mathrm{A} \\
\left({ }^{\circ} \mathrm{C}\right)\end{array}$} & \multicolumn{2}{c}{$\begin{array}{c}\text { Kolektor } \\
\mathrm{B}\left({ }^{\circ} \mathrm{C}\right)\end{array}$} \\
\cline { 2 - 5 } & $\min$ & $\max$ & in & $\max$ \\
\hline $0,008 \mathrm{~kg} / \mathrm{s}$ & 1,3 & 1,7 & 1,35 & 1,65 \\
\hline $0,010 \mathrm{~kg} / \mathrm{s}$ & 1,1 & 1,4 & 1,2 & 1,4 \\
\hline $0,030 \mathrm{~kg} / \mathrm{s}$ & 0,4 & 0,6 & 0,45 & 0,55 \\
\hline
\end{tabular}

Berdasarkan nilai minimal dan maksimal dari selisih temperatur inlet dan outlet, kolektor B memiliki rentang temperatur yang lebih konstan daripada kolektor A. Hal ini disebabkan pada kolektor B yang menggunakan PCM dapat menyimpan panas yang diserap dari radiasi lampu. Sehingga ketika sinar radiasi lampu naik atau turun, PCM dapat menstabilkan panas yang diterima oleh fluida kerja.

Gambar 4 menunjukkan bahwa semakin tinggi laju aliran massa fluida maka selisih temperatur inlet dan outlet akan semakin rendah. Begitu juga sebaliknya apabila laju aliran massa fluida semakin rendah maka selisih temperatur akan semakin tinggi. Hal ini disebabkan laju aliran massa fluida merupakan hasil dari perkalian debit air dan massa jenis air. Ketika debit air tinggi, maka lama kontak antara fluida dan dinding pipa air akan semakin kecil sehingga panas yang dibawa semakin sedikit begitu juga sebaliknya.
Gambar 5 juga menunjukkan bahwa semakin besar laju aliran massa, maka nilai dari selisih inlet dan outlet akan semakin stabil. Ketidakstabilan ini terjadi karena ketika laju aliran besar, maka proses sirkulasi fluida kerja pada reservoir akan semakin cepat merata sehingga kenaikan temperatur inlet menjadi konstan. Ketika laju aliran fluida kecil, maka proses sirkulasi dalam reservoir akan semakin lama sehingga kenaikan temperatur inlet menjadi tidak stabil.

\subsection{Efisiensi}

Menentukan efisiensi pada pemanas air kolektor tabung menggunakan persamaan berikut ini.

$$
\eta=\frac{Q \text { aĩ }}{(0,5 \times \mathbb{N} \times A c x I(t))]+(0,5 \times N \times A c x I(t) \times 0,7)} \times 100 \%
$$

\section{Dengan:}

$\eta \quad=$ efisiensi kolektor (\%)

$Q$ air = panas yang diserap oleh air sebagai fluida kerja,

$\mathrm{N} \quad=$ jumlah kolektor

Ac = luasan permukaan kolektor

$\mathrm{I}(\mathrm{t}) \quad=$ intensitas sinar radiasi yang diterima kolektor

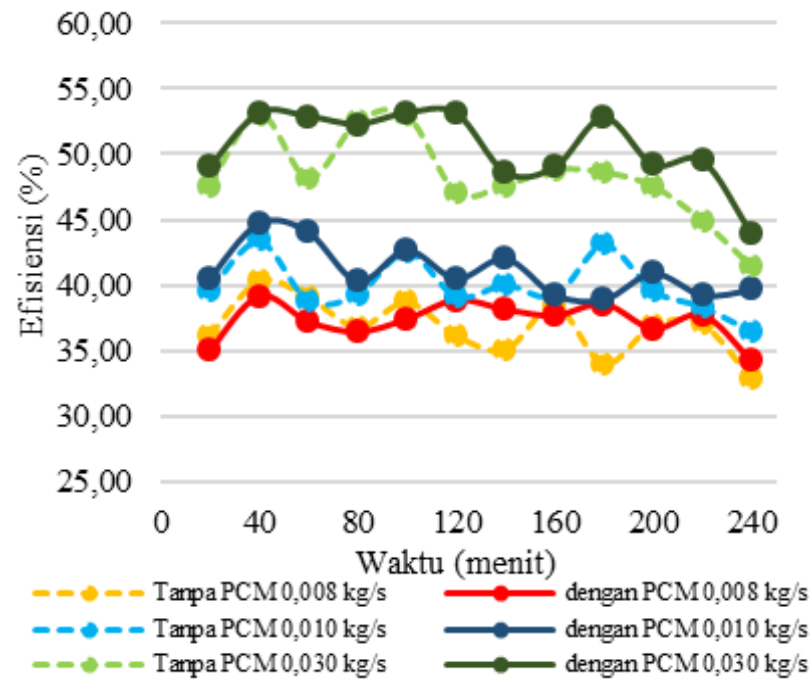

Gambar 6. Efisiensi pemanas air kolektor tabung

Berdasarkan gambar 6, nilai efisiensi pada pemanas air menggunakan kolektor $A$ dan kolektor $B$ tidak memiliki perbedaan yang besar namun penambahan PCM dapat mempengaruhi efisiensi kolektor tabung menjadi lebih besar. Hal ini dapat dilihat dari rata - rata efisiensi setiap laju aliran massa. Pada laju aliran $0,008 \mathrm{~kg} / \mathrm{s}$ kolektor A memiliki efisiensi $36,81 \%$ sedangkan kolektor lebih besar yaitu 37,27\%. Pada laju aliran $0,010 \mathrm{~kg} / \mathrm{s}$ kolektor A memiliki efisiensi $39,97 \%$ sedangkan kolektor B lebih besar yaitu $41,08 \%$. Pada laju aliran $0,030 \mathrm{~kg} / \mathrm{s}$ kolektor A memiliki efisiensi 48,3\% sedangkan kolektor B lebih besar yaitu $50,53 \%$.

Gambar 5 menunjukkan nilai efisiensi kolektor tabung dipengaruhi oleh laju aliran massa fluida kerja. Efisiensi kolektor tabung tertinggi terjadi pada kolektor $B$ dengan laju aliran massa $0,030 \mathrm{~kg} / \mathrm{s}$ pada menit $\mathrm{ke}-$ 60 yaitu 53,64\%. Sedangkan efisiensi terendah terjadi pada kolektor A dengan laju aliran massa $0,008 \mathrm{~kg} / \mathrm{s}$ 
pada menit ke - 240 yaitu $32,82 \%$. Dapat disimpulkan bahwa semakin tinggi laju aliran massa, maka nilai efisiensi kolektor tabung juga akan semakin tinggi, begitu pula sebaliknya.

\subsection{Temperatur Glass tube dan Absorber}

Penambahan PCM pada kolektor tabung dapat menyebabkan perbedaan temperatur pada glass tube dan absorber dari kolektor tanpa menggunakan PCM.

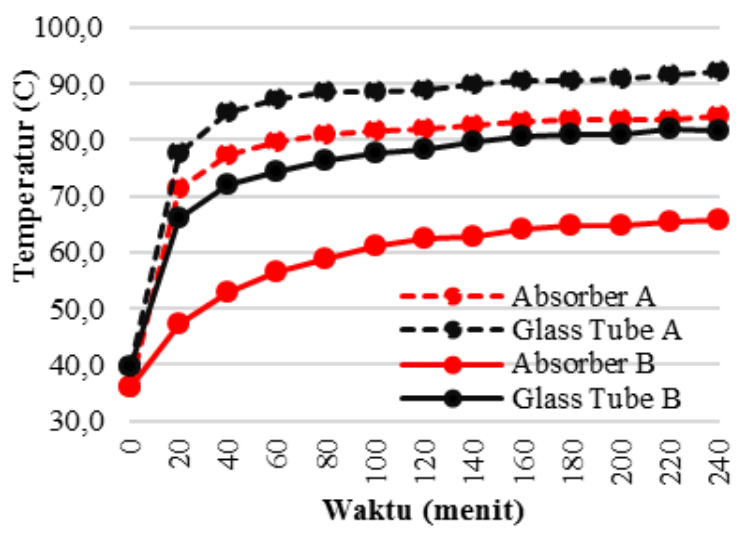

Gambar 7. Temperatur glass tube dan absorber

Berdasarkan gambar 7, perbedaan temperatur glass tube dan absorber pada kolektor A dan kolektor $B$ terlihat signifikan bahwa glass tube dan absorber pada kolektor A lebih tinggi dari pada kolektor B. Temperatur glass tube pada kolektor A memiliki temperatur maksimal sebesar 92,3 oC sedangkan pada kolektor B hanya 81,7 oC. Temperatur absorber pada kolektor A memiliki temperatur maksimal sebesar 84,2 oC sedangkan pada kolektor B hanya 65,7 oC. Temperatur glass tube kolektor B lebih rendah 11,5\% dari kolektor $\mathrm{A}$ dan temperatur absorber pada kolektor $B$ lebih rendah $22 \%$ dari kolektor $A$. Hal tersebut disebabkan penggunaan PCM pada kolektor B dapat menyerap dan menyimpan sebagian kalor pada kolektor sehingga temperatur absorber dan glass tube menjadi turun. Material yang sering mendapat panas cenderung lebih mudah mengalami kerusakan oleh karena itu penggunaan PCM dapat menambah umur pakai kolektor tabung. Penelitian ini telah membuktikan penelitian Felinski et al. (2017) bahwa penggunaan PCM dapat menambah umur pakai kolektor tabung.

\section{Simpulan}

Penambahan Phase Change Material (PCM) dapat meningkatkan efisiensi pada kolektor. Hal ini terbukti pada laju aliran $0,008 \mathrm{~kg} / \mathrm{s}, 0,010 \mathrm{~kg} / \mathrm{s}$, dan $0,030 \mathrm{~kg} / \mathrm{s}$ Kolektor tabung A memiliki rata - rata efisiensi sebesar 36,81\%, 39,97\%, dan 48,3\% sedangkan kolektor B memiliki efisiensi sebesar $37,27 \%$, 41,08 \%, dan 50,53 \%. Dengan penambahan PCM dapat mengurangi heat loss pada kolektor karena sifatnya yang dapat menyimpan panas sehingga kolektor tabung dapat menyerap panas lebih efektif daripada tanpa menggunakan PCM.

Perbedaan laju aliran massa fluida sangat berpengaruh pada efisiensi kolektor tabung. Pada proses charging, efisiensi tertinggi terjadi pada kolektor B dengan laju aliran massa $0,030 \mathrm{~kg} / \mathrm{s}$ yaitu $51,36 \%$ dan efisiensi terendah terjadi pada kolektor $A$ dengan laju aliran massa $0,008 \mathrm{~kg} / \mathrm{s}$ yaitu $35,09 \%$ maka semakin tinggi laju aliran massa fluida kerja pada kolektor menyebabkan efisiensi semakin tinggi pula.

\section{Ucapan Terima Kasih}

Ucapan terima kasih kepada Staf Jurusan Teknik Mesin Universitas Jember yang telah membimbing hingga artikel dapat diselesaikan dengan baik.

\section{Daftar Pustaka}

[1] Lubis, A. 2007. Energi Terbarukan dalam Pembangunan Berkelanjutan. Jurnal Teknik Lingkungan 8(2): 155 - 162.

[2] Bhowmik N. C, and Mullick S. C. 1985. Calculation Of Tubular Absorber Heat Loss Factor. Journal of Solar Energy. 35: 219-225.

[3] Misrha, R. K., Garg, V. \& Tiwari, G. N. 2015. Thermal Modeling and Development of Characteristic Equations of Evacuated Tubular Collector (ETC). Solar Energy 1: 581-585.

[4] Devanarayanan, \& K. Murugavel, K. K. 2014. Integrated collector storage solar water heater with compound parabolik concentrator development and progress. Renewable and Sustainable Energy Reviews. 39: 51-64.

[5] Misrha, R, K., Garg, V. \& Tiwari, G. N. 2017. Energy matrices of u-shaped evacuated tubular collector (etc) integrated with compound parabolic concentrator (CPC). Solar Energy 150: 531-539.

[6] Zhongyuan S., Shengyan G., \& Kambiz V. 2017. Modeling and simulation of ray tracing for compound parabolic thermal solar collector. International Communications in Heat and Mass Transfer 87: 169 - 174.

[7] Felinski, P., \& Sekret, R. 2016. Effect of a low cost parabolic reflector on the charging efficiency of an evacuated tube collector/storage system with a PCM. Solar Energy 144: 758-766.

[8] Felinski, P., \& Sekret, R. 2017. Experimental study of evacuated tube collector/storage system containing paraffin as a PCM. Solar Energy 114: 1063-1072. 